\title{
O PERFIL DOS ACADÊMICOS EM FORMAÇÃO INICIAL NO CONTEXTO DO PIBID- BIOLOGIA UEM
}

\author{
Glaucia Britto Barreiros, Dulcinéia Ester Pagani Gianotto \\ Universidade Estadual de Maringá - UEM. E-mail: glaucia_bb@hotmail.com
}

\section{RESUMO}

As experiências na formação inicial norteiam a construção do perfil do futuro profissional docente. Apenas a leitura de teorias que complementam a pratica do estágio, é pouco para apresentar todos os dilemas enfrentados na prática pelos licenciandos. Para desenvolver os saberes docentes e transformar a prática em experiências reflexivas, ações como a do PIBID (Programa de Bolsa de Iniciação à Docência) foram propostas pelo governo federal. Nesse sentido o trabalho é de caráter qualitativo, e tem por objetivo investigar os participantes do PIBID- Biologia da UEM, identificando qual o perfil destes participantes. Os dados foram submetidos a análise de conteúdo de Bardin (1977). Dos 20 participantes, 18 responderam e entregaram o diário com as questões e sobre estes foi elaborada a análise e discussão presentes neste artigo. O perfil idealizado pelos participantes se aproxima muito dos propostos pelos principais autores que abordam a formação de professores e a perspectiva reflexiva.

Palavras-chave: Identidade docente, Formação inicial, Prática reflexiva, Ensino de Biologia, PIBID.

\section{PROFILE OF STUDENTS IN INITIAL TRAINING IN THE CONTEXT OF BIOLOGY PIBID - UEM}

\begin{abstract}
The experiences in initial training guide the construction of the future teaching professional profile. Just reading theories that complement the practice stage, is unlikely to provide all the dilemmas faced in practice by licensees. To develop teacher knowledge and transforming practice in reflective experiences, actions like PIBID (Program Initiation to Teaching Exchange) have been proposed by the federal government. In this sense the work is qualitative, and aims to investigate the participants PIBID- Biology of EMU, which identifies the profile of these participants. The data were subjected to content analysis of Bardin (1977). Of the 20 participants, 18 responded and delivered daily with these issues and was prepared to analyze and discuss within this article. The profile designed by the participants is very close to the proposed by leading authors that address teacher training and reflective perspective.
\end{abstract}

Keywords: Teacher identity, Initial Training, Reflective Practice, Teaching Biology, PIBID. 


\section{INTRODUÇÃO}

A questão da formação dos professores precisa, constantemente, ser discutida, em especial a formação inicial. A pesquisa sobre o Ensino de Ciências, peculiarmente o Ensino de Biologia, tem crescido e os resultados, evidenciam a importância dessas investigações no sentido de contribuir com uma transformação do professor e de suas ações. Apenas traçar diferenças entre "bons" e "maus" professores não resolve e muito menos contribui para uma inovação do ensino (GIL-PEREZ 2003, KRASILICHK, 2004). Entende-se que a renovação das concepções dos professores inicia-se na formação inicial, durante o estágio supervisionado. O estágio e a instrumentação pedagógica são de extrema importância, pois proporcionam o primeiro contato do licenciando com a escola, são os primeiros testes e experimentações no "laboratório" que a sala de aula se caracteriza. Para desenvolver as demandas presentes na atividade do professor, os licenciandos precisam desenvolver o que Pimenta (2005), chama de saberes da docência. Segundo a autora estes saberes, iniciam-se pelos saberes da experiência, que são aqueles construídos no cotidiano com a escola, os planejamentos, os colegas, entre outros. Outro saber docente é o do conhecimento, que vai além dos conceitos e mergulha na compreensão do significado de ensinar aquele conteúdo. E por fim os saberes pedagógicos que segundo a autora emanam dos dois anteriores, e que corrobora com a reflexão sobre o que se faz na prática.

Nesse sentido, pensando em uma nova opção para ampliar o período de troca entre a escola e o os licenciandos, foi criado o Projeto Institucional de Bolsa de Iniciação à Docência (PIBID). A iniciativa de implementação do projeto PIBID é do governo Federal, a partir do ano de 2010. O intuito é proporcionar a integração entre participantes, com os professores da escola e os orientadores das universidades, aumentando o tempo de experiência no âmbito da escola, segundo a Capes (2014): "O PIBID é uma iniciativa para o aperfeiçoamento e a valorização da formação de professores para a educação básica".

O conceito da formação de professores de forma reflexiva, que se caracteriza pela valorização da experiência e da reflexão na experiência vivenciada pelos professores é compartilhado por muitos autores (SCHÕN, 1992; NÓVOA, 1992; PIMENTA, 2002; PERRENOUD, 2002; ALARCÃO, 2003; ZEICHNER, 2008). Destacando-se como precursor e principal autor Donald A. Schõn, que iniciou no movimento "reflection-in-action", um incentivo as pesquisas sobre professores pesquisadores e reflexivos de sua prática. Corroborando com os pesquisadores do ensino reflexivo Freire (1996), um educador importantíssimo no Brasil que incentivou a mudança na maneira de ensinar, também defende uma reflexão crítica sobre a prática e a coloca como peça chave para que o ensino seja libertador e para que o professor alcance sua autonomia e promova 
esta autonomia ao seu educando. Freire (1996), afirma que: "na formação permanente dos professores, o momento fundamental é o da reflexão crítica sobre a prática. É pensando criticamente a prática de hoje ou de ontem que se pode melhorar a próxima prática." (p. 39).

Partindo dos princípios teóricos de professor reflexivo e as metodologias de ensino, a partir da análise das concepções dos licenciandos, faz-se necessário compreender algumas questões como: Como é o perfil do acadêmico que participa do projeto PIBID? E em que medida os acadêmicos em formação inicial, participantes do PIBID apresentam características reflexivas? 0 objetivo deste trabalho é analisar como se caracteriza o perfil dos acadêmicos em formação inicial de Biologia, participantes do PIBID observando se há uma construção da prática reflexiva por estes participantes.

\section{METODOLOGIA}

Na busca por contribuir para os estudos sobre a reflexão na formação de professores a presente pesquisa é de caráter qualitativo, que também recebe o nome de naturalística fenomenológica, e se configura por investigar e descrever sem preocupação com resultados, mas trazendo como foco o processo da pesquisa e os seus envolvidos, pois se apresenta de maneira subjetiva, onde as variáveis não podem ser controladas (LUDKE \& ANDRÉ, 1986). Este artigo é fruto da análise parcial de dados da dissertação de mestrado sobre a formação inicial de professores no contexto do projeto PIBID. A pesquisa foi aprovada no Comitê de ética na Pesquisa $(\mathrm{CEP})^{1}$.

Os sujeitos da pesquisa foram vinte acadêmicos do curso de Ciências Biológicas participantes do projeto PIBID-Biologia. O instrumento utilizado para o levantamento dos dados foi o diário de aula com questões pré-definidas para identificar o perfil desses acadêmicos. Alguns trechos dessas foram utilizadas nos resultados e discussões, para identifica-los e diferenciá-los enumeramos os 18 diários, estipulando a sigla Diário 1 (D1) até o Diário 18 (D18). Os dados foram submetidos à análise de conteúdo utilizando-se do cruzamento entre os dados coletados por meio da categorização de respostas proposta por Bardin (1977, p. 117), que é "uma operação de classificação de elementos constitutivos de um conjunto, por diferenciação e, seguidamente, por reagrupamento segundo gênero (analogia), com os critérios previamente definidos". Nesse sentido, as respostas dos diários da prática pedagógica foram categorizados a fim de identificar as unidades de significados que demonstrem as visões dos acadêmicos sobre o perfil de um participante do PIBID.

\footnotetext{
${ }^{1}$ Número de protocolo do CEP - CAAE: 25702814.9.0000.0104. 


\section{RESULTADOS}

Durante a intervenção participaram das ações do grupo 19 dos 20 participantes regulares do projeto. Desses apenas 18 acadêmicos entregaram os diários e sobre estes foi elaborada a análise. Os participantes foram questionados antes de preencherem os diários de aula e tais questionamentos buscavam traçar um perfil dos participantes do PIBID-Biologia. Com base nas respostas as questões do perfil presente nos diários de aula, obtivemos os seguintes resultados:

QUADRO 1. Perfis delineados pelos acadêmicos.

\begin{tabular}{|c|c|c|}
\hline \multicolumn{2}{|c|}{ Perfil traçados pelos participantes } \\
\hline Perfis & Diários & (\%) \\
\hline $\begin{array}{c}\text { Apresentam apenas características } \\
\text { pessoais }\end{array}$ & D2, D3, D5, D10, D12, D15 & $\begin{array}{c}33,33 \% \\
\text { (6 acadêmicos) }\end{array}$ \\
\hline $\begin{array}{c}\text { Apresentam características pessoais } \\
\text { e aprofundam a respostas }\end{array}$ & D8, D9, D13, D14, D16, D18 & $\begin{array}{c}33,33 \% \\
\text { (6 acadêmicos) }\end{array}$ \\
\hline $\begin{array}{c}\text { Considerem as problemáticas da } \\
\text { área de ensino/ Melhorar a } \\
\text { educação de forma geral }\end{array}$ & D1, D4, D6, D7, D11, D17 & $\begin{array}{c}33,33 \% \\
\text { (6 acadêmicos) }\end{array}$ \\
\hline
\end{tabular}

QUADRO 2. Considerações dos acadêmicos quanto a atender ou não o perfil para ser um participante do PIBID.

\begin{tabular}{|c|c|c|}
\hline \multicolumn{3}{|c|}{ Considerações sobre atender ou não o perfil para ser um participante do PIBID } \\
\hline Atendem ao perfil & Diários & (\%) \\
\hline $\begin{array}{c}\text { "Sim" / "Creio que sim" / "Quando tive o } \\
\text { primeiro contato com sala de aula, foi paixão à } \\
\text { primeira vista" }\end{array}$ & $\begin{array}{c}\text { D3, D4, D5, D6, D7, D9, } \\
\text { D10, D11, D12, D14, } \\
\text { D15, D16, D17, D18 }\end{array}$ & $\begin{array}{c}76,47 \% \\
\text { (13 participantes) }\end{array}$ \\
\hline Não atendem ao Perfil & Diários & (\%) \\
\hline $\begin{array}{c}\text { "Faço o possível" / "às vezes falhamos quanto } \\
\text { a isso" / "Em partes" / "Mais ou menos" }\end{array}$ & D1, D2, D10, D13 & $\begin{array}{c}\text { 23, 52\% } \\
\text { (4 participantes) }\end{array}$ \\
\hline
\end{tabular}

QUADRO 3. Motivações dos participantes do projeto PIBID.

\begin{tabular}{|c|c|c|}
\hline \multicolumn{3}{|c|}{ Motivações para participação no projeto PIBID } \\
\hline Porque estou no Projeto PIBID? & Encontradas nos diários & (\%) \\
\hline "Gosto muito da licenciatura" & D1, D2, D5, D9, D10, D11, & $70,59 \%$ \\
"Sempre gostei de dar aulas" & D13, D14, D15, D16, D17, & D18 \\
"É muito bom gosto de fazer pare dele" & (12 acadêmicos) \\
\hline "Adoro o PIBID" & D7, D12, D13, D14, & $\begin{array}{c}23,53 \% \\
\text { (4 acadêmicos) }\end{array}$ \\
\hline
\end{tabular}




\begin{tabular}{|c|c|c|}
\hline $\begin{array}{l}\text { "A bolsa ajuda muito" } \\
\text { "Precisava de uma bolsa" } \\
\text { "A oportunidade de conseguir um estágio } \\
\text { remunerado na UEM" }\end{array}$ & $\begin{array}{c}\text { D1, D2, D4, D6, D9, D14, } \\
\text { D15, D17, D18 }\end{array}$ & $\begin{array}{c}52,94 \% \\
\text { (9 acadêmicos) }\end{array}$ \\
\hline $\begin{array}{l}\text { "Conhecer a docência" } \\
\text { "Melhorar a didática" }\end{array}$ & $\begin{array}{c}\text { D5, D6, D9, D10, D13, D15, } \\
\text { D18 }\end{array}$ & $\begin{array}{c}41,18 \% \\
\text { (7 acadêmicos) }\end{array}$ \\
\hline $\begin{array}{l}\text { "Procurei...subsídio uma orientação e } \\
\text { discussão sobre aspectos educacionais" } \\
\text { "Discutir sobre problemas educacionais" } \\
\text { "O programa promove a integração entre a } \\
\text { educação superior e a educação básica" }\end{array}$ & D3, D9, D16, D18 & $\begin{array}{c}23,53 \% \\
\text { (4 acadêmicos) }\end{array}$ \\
\hline $\begin{array}{l}\text { "Boa experiência como professor" } \\
\text { "Viso uma pós-graduação na área" }\end{array}$ & $\begin{array}{l}\text { D4, D9, D10, D11, D14, } \\
\text { D15, D16, D18 }\end{array}$ & $\begin{array}{c}45,05 \% \\
\text { (8 acadêmicos) }\end{array}$ \\
\hline $\begin{array}{c}\text { "Já tinha participado de duas iniciações } \\
\text { científicas" } \\
\text { "Abdiquei de outros projetos" } \\
\text { "Não havia gostado do estágio no } \\
\text { laboratório" }\end{array}$ & $\begin{array}{c}\text { D5, D6, D9, D12, D15, D16, } \\
\text { D17 }\end{array}$ & $\begin{array}{c}41,18 \% \\
\text { (7 acadêmicos) }\end{array}$ \\
\hline $\begin{array}{l}\text { "Acho importante ter em sua formação } \\
\text { inicial um projeto dessa qualidade" } \\
\text { "Aprimorar minha formação inicial" }\end{array}$ & D7, D12 & $\begin{array}{c}11,76 \% \\
\text { (2 acadêmicos) }\end{array}$ \\
\hline "Testar coisas novas" & D15 & $\begin{array}{c}5,88 \% \\
\text { (1 acadêmico) }\end{array}$ \\
\hline $\begin{array}{c}\text { "Me fez escolher ser professor como } \\
\text { carreira" }\end{array}$ & $\mathrm{D} 2$ & $\begin{array}{c}5,88 \% \\
\text { (1 acadêmico) }\end{array}$ \\
\hline "Embora as vezes seja bem estressante" & D14 & $\begin{array}{c}5,88 \% \\
\text { (1 acadêmico) }\end{array}$ \\
\hline "Carga horária semanal baixa" & D15 & $\begin{array}{c}5,88 \% \\
\text { (1 acadêmico) }\end{array}$ \\
\hline
\end{tabular}

\section{DISCUSSÃO}

Neste artigo a proposta foi analisar e identificar o perfil dos participantes do projeto PIBIDBiologia. As reflexões dos participantes acerca do perfil foram realizadas com os conceitos sobre os saberes da docência, à luz de Pimenta (2005) além dos pressuposto de Schõn (1992) e Freire (1996) acerca da reflexão sobre a prática docente.

Como sabemos é complexo realizar generalizações na análise, pois dentro do grupo de participantes identificamos alunos que eram integrantes do projeto desde o início enquanto outros participavam apenas há alguns meses e ainda se familiarizavam com o ambiente Entretanto baseados nas respostas traçamos algumas categorias que se destacaram nos trechos de suas respostas com relação ao perfil traçado por eles para ser um "pibidiano" (participante do PIBID). 
Ao responderem sobre como eles acreditam ser o perfil dos participantes do PIBID, obtivemos duas formas de interpretação (Quadro I): a primeira em relação às questões pessoais de cada participante onde eles apresentam características pessoais para traçar o perfil e a segunda com questões não tão pessoais, mas que levam em consideração as problemáticas da área de ensino e buscam não apenas o aprimoramento pessoal, mas melhorar a educação de forma geral. Nas falas os acadêmicos citaram que o aluno participante do PIBID necessita de comprometimento, empenho, criatividade, curiosidade, iniciativa, vontade, interesse, participação e acima de tudo que goste da área da licenciatura. A respostas dos participantes apontaram que, como o PIBID é um projeto com o intuito de inovar o ensino, quem participa dele precisa ter características de futuros profissionais professores comprometidos. Noto na fala dos alunos e no contexto atual que falta, muitas vezes, esse comprometimento dos profissionais com aquilo que eles escolheram realizar em suas carreiras. Nesse sentido observamos que o perfil que eles apontam como participante precisa fugir desta realidade e já em sua formação o professor precisa compreender que ensinar é uma especificidade humana, uma escolha profissional que deve ser realizada de forma consciente levando em consideração as exigências necessárias. Essa exigência do Ensino de forma peculiar e humana é ressaltada por Freire (1996) onde aponta fatores importantes em que o Ensino exige algumas peculiaridades do professor, tais como: segurança; competência profissional; generosidade; comprometimento; compreender que a educação é uma forma de intervenção do mundo; que ensinar exige liberdade e autoridade; saber escutar; compreender que a educação é ideológica; exige ainda disponibilidade de diálogo e por fim querer bem à aquele que se ensina (FREIRE, 1996).

Identificamos na fala dos acadêmicos que eles compreendem os dilemas atuais e sabem qual o perfil necessário para se lutar pela educação neste contexto. E ao apresentarem essas características e adentrarem ao projeto demonstram ter disponibilidade para discussões sobre o que ensinar, como ensinar e, buscando esse aperfeiçoamento desde sua formação apontam uma preocupação e respeito a quem eles irão ensinar, assim como Freire (1996) defende. Schõn (1992) também define o que acredita ser o perfil do professor e ao explicar a diferença entre o conhecimento prático e os saberes escolares destaca algumas características para ser um professor que leva em consideração a reflexão-na-ação: "Se o professor quiser familiarizar-se com este tipo de saber tem de Ihe prestar atenção, ser curioso, ouvi-lo, surpreender-se, e actuar como uma espécie de detective que procura descobrir as razões que levam as crianças a dizer certas coisas. (SCHÕN, 1992, p. 82). Observamos que ele aponta algumas das características citadas nas respostas dos participantes do PIBID como interesse, curiosidade. E junto a estas Schõn acrescenta 
outras que somente nas atuações os acadêmicos em formação poderão compreender. Ao considerarmos as características do profissional professor a partir das definições de Freire e Schõn subentendesse que os acadêmicos ao traçarem o perfil de um participante de um projeto de ensino, esperam também que tais atributos sejam necessários para os docentes atuantes.

De forma geral todas as respostas trouxeram atributos pessoais para definir o perfil, entretanto numa segunda abordagem observamos que alguns alunos aprofundam este perfil, e consideram que para ser um pibidiano é preciso se preocupar com as questões educacionais e com a licenciatura (Quadro I). Os acadêmicos incorporam nas suas respostas a importância de se identificar e lutar por uma melhora no contexto educacional atual. Notamos na fala deles essa preocupação em modificar a visão simplista de dar aulas, e de ser professor, como observamos também nos autores que realizam a análise crítica da formação atual dos professores. Um deles, Carvalho (2011), ressalta:

[...] "conceber a formação do professor como uma profunda mudança didática que deve questionar as concepções docentes de senso comum, começando por aquela afirmação de que "ensinar é fácil. Constatamos assim a necessidade de um profundo conhecimento da matéria - sem comparação com visões reducionistas habituais - e da apropriação de uma concepção do ensino/aprendizagem das Ciências como construção de conhecimentos, isto é, como uma pesquisa dos alunos e dos professores" (CARVALHO, 2011, p. 66).

Ainda nessa perspectiva alguns acadêmicos aprofundaram essa visão de como seria o perfil de um pibidiano e apresentaram respostas bastante complexas (Quadro I):

D9 - "O perfil do aluno que chega ao PIBID reflete a demanda reprimida que o Brasil não atendeu durante alguns anos. Foi apenas em 2010 que o governo resolveu investir em bolsas para alunos dos cursos de licenciatura para a Educação. O aluno que ingressa no PIBID, tem como perfil valorizar a docência nas escolas, incentivando os estudantes de licenciatura no ensino médio, valorizando assim o magistério. A convivência dos graduados com o cotidiano das escolas aumenta, estimulando o ingresso e permanência na carreira de docente."

Essas respostas falam de criticidade acerca do sistema de ensino e as metodologia de ensino-aprendizagem, vontade de pesquisar e discutir a respeito da educação. O acadêmico D9, trouxe ainda o porquê da idealização do projeto PIBID pelo governo federal, apontando a falta de profissionais das licenciaturas o que levou a criação do projeto com o intuito de valorizar os estudantes da licenciatura e incentivá-los durante a graduação. Como pesquisadoras acreditamos que o projeto PIBID é de extrema importância na formação e esta nova proposta que se concretiza desde 2010 é, sem dúvida, um diferencial na formação inicial de professores, e corrobora com Schõn acerca dos pressupostos do ensino prático durante a formação inicial e do próprio processo 
ensino-aprendizagem construído sob a ótica da reflexão-na-ação. E, por este motivo uma das falas de um acadêmico nos chamou a atenção:

D8 - "Eu acredito, de verdade que todos os licenciandos da licenciatura deveriam ter a oportunidade de participar do programa. Penso que para participar do PIBID, no mínimo, deve-se ter vontade/intenção de ser professor. Não incluo gostar porque sinto que isso só é possível depois de passar pelas experiências que o programa possibilita, da mesma forma que excluo ter didática ou explicar bem, isso nós aprendemos dentro do programa."

Concordamos com essa ideia de que todos os futuros professores deveriam ter este contato prático e reflexivo da prática, que o PIBID se propõe a realizar, visto que sem conhecer como é o ambiente onde irão trabalhar gostar fica complicado. Somente gostamos, após vivenciar as experiências do projeto, consideramos que do mesmo modo o futuro professor necessita de um contato maior que o realizado nos estágio supervisionados, presentes nas grades curriculares das instituições de ensino superior. Defendemos que devem, o quanto antes, compreender seu papel como professor e buscar pesquisar e propor novas formas de trabalhar nesse ambiente favorecendo o processo ensino-aprendizagem e a educação como um todo. Notamos na resposta de D8, que o acadêmico foge da visão simplista de que ser professor exige algum dom, e se pauta na formação por meio da experiência e reitera que, em sua opinião, gostar, ter didática e fluência ao explicar são habilidades e competências adquiridas durante esta formação, o que faz dos estágios supervisionados e do próprio projeto PIBID, uma ferramenta para a construção de profissionais competentes dentro do sistema educacional de ensino, o que vai além de apenas mais uma disciplina a ser cumprida pelos acadêmicos no currículo. Segundo Pimenta (2005), p. 26: "A especificidade da formação pedagógica, tanto a inicial como a contínua, não é refletir sobre o que se vai fazer, nem sobre o que se deve fazer, mas sobre o que se faz".

Com o intuito de identificar como o acadêmico se qualifica em suas atuações dentro dos pressupostos do projeto e se ele gosta ou não de participar deste, questionamos se ele acredita atender o perfil traçado por ele. Dos participantes apenas um não respondeu, desses 76,47\% (13 participantes) acreditam que "Sim" (Quadro II), atendem ao perfil que eles mesmo traçaram, tais respostas afirmam e acrescentam várias justificativas que acompanham o perfil concebido por eles, já analisado acima. Nas falas aparecem: o gosto e a paixão pela licenciatura, a busca por aprender e aprimorar-se, o estudo da prática e teoria do ensino (métodos e técnicas), a melhora na organização e planejamento de atividades e a troca de experiências dentro do grupo. Os demais $23,52 \%$ (4 participantes) não foram complemente enfáticos e utilizaram termos como "faço o possível"; "mais ou menos"; "em partes", "as vezes falhamos" (Quadro II). 
Apesar de serem a minoria identificamos nesta incerteza se atendem ou não ao perfil idealizado, uma auto reflexão que demonstra uma criticidade dentro da atuação dele no projeto PIBID. Se refletirmos como podemos ter certeza de que "Sim"? Atendo ao perfil e tenho um desempenho ótimo como professor dentro do projeto PIBID. É surreal, e por isso concordamos com o acadêmico em sua autocrítica, ele admite possíveis erros e as alterações do planejamento inicial. Denota-se então neste fala um pensamento reflexivo e autocrítico, um olhar para o que se realizou e a busca por melhorar. Sendo este o primeiro passo para a prática reflexiva, visto que o conhecimento é uma construção humana e é passível de erros, com eles nós refletimos e reaprendemos. O aluno deve errar e perceber onde errou para aprender, o professor também. Nesse mesma perspectiva o trecho do acadêmico que diz: "às vezes falhamos", mas tenho muito a melhorar", "eu faço pouco para mudar", assumem os fracassos e as dificuldades. Concordamos que é esse processo que constrói o profissional professor, e nesse aspecto o PIBID realiza e explora essas experiências. Nessas falas os acadêmicos apresentam-se autocríticos com justificativas coerentes e demonstram que estão no processo e de forma consciente. Entretanto isso não quer dizer que os outros que responderam que "Sim", não sejam.

Para complementar o perfil dos acadêmico participantes do PIBID-Biologia, questionamos se eles realmente gostam de participar do projeto ou é por outros motivos como, por exemplo, a remuneração recebida. Dos 18 que entregaram os diários, apenas um se absteve de responder essa questão. Dos 17 que responderam nenhum afirmou não gostar de participar do projeto, alguns buscaram conhecer e depois gostaram (Quadro III): D13 - "Quando fiz a inscrição pensei na bolsa, mas quando dei minha primeira aula comecei a gostar bastante, hoje estou por amor.". Os acadêmicos apresentam diversos motivos para participar (Quadro III), porém gostar do que eles realizam (70,59\%), receber uma remuneração (52,94\%), ter a experiência durante a formação (45, 05\%), conhecer a docência e se aprimorar $(41,18 \%)$, ter tido experiências ruins em outros laboratórios $(41,18 \%)$ e discutir sobre as questões educacionais $(23,53 \%)$, são as principais motivações. Entretanto existe uma discrepância na opinião dos alunos quanto a carga de atividades exercidas e se estas são mais fáceis ou mais difíceis que outros projetos, como o de iniciação científica. Outras falas, afirmam também que ao adentrar no PIBID algo mudou, as concepções que eles apresentavam anteriormente não são mais as mesmas, como observamos no trecho a baixo:

D18 - "Quando entrei para o PIBID, em abril de 2010, meu objetivo era conhecer um pouco mais sobre dar aula, me desinibir e ganhar um dinheiro, principalmente. Com o tempo um mundo muito maior foi me apresentando esse mundo mostrava e mostra, que a educação é capaz de 
mudar as coisas, apesar de todas as dificuldades. Atualmente meu foco não é mais o dinheiro, mas sim o prazer de estudar e educar."

\section{CONCLUSÃO}

O perfil idealizado pelos participantes se aproxima muito dos propostos pelos principais autores (FREIRE, 1996; SCHÕN, 1992; PIMENTA, 2005) que abordam a formação de professores sobre a perspectiva reflexiva. A opinião dos acadêmicos quanto a se atendem ou não o perfil delineado por eles, denotou-se que 76,47\% (13 participantes) afirmam apresentar tal perfil. Porém notamos que nos outros $23,52 \%$ (4 participantes) que em suas falas trouxeram dúvida e fugiram do "sim", em suas respostas ao justificar o por que não atendem tal perfil, demonstraram um alto nível de reflexão e autocrítica. Observamos ainda que existem diversos motivos para os acadêmicos participarem do projeto. $E$ as respostas são dotadas de discursos sobre a educação e a importância de se repensar a forma de ensinar. Sem dúvida o que podemos observar na fala desses acadêmicos é que ouve uma transformação após adentrarem ao projeto, como se eles estivessem procurando onde se encaixar e encontraram. Acreditamos que investigar e analisar as concepções dos participantes do PIBID é uma forma de verificar o andamento do projeto e assim contribuir para as pesquisas sobre o ensino, a formação de professores e a prática reflexiva.

\section{REFERÊNCIAS}

ALARCÃO, Isabel. Professores reflexivos em uma escola reflexiva. Cortez Editora, São Paulo, (2) p. 40-57, 2003.

BARDIN, L. Análise de conteúdo. Lisboa: Edições 70, 1977.

CAPES, Coordenação de Aperfeiçoamento de Pessoal de Nível Superior. Disponível em: http://www.capes.gov.br/educacao-basica/capespibid/pibid Acesso em: 31/07/2014.

FREIRE, Paulo. Pedagogia da autonomia: saberes necessários à prática educativa. São Paulo: Paz e Terra, 1996.

KRASILCHIK, Myriam. Prática de ensino de Biologia. Editora Universidade de São Paulo, 2004.

LUDKE, M.; ANDRÉ, M. E. D. A. Pesquisa em educação: abordagens qualitativas. São Paulo: EPU, 1986.

NÓVOA, A. Formação de Professores e profissão docente. In: Nóvoa (org.) Os professores e a sua formação, Lisboa, Dom Quixote, 1992.

PIMENTA, Selma Garrido; GHEDIN, Evandro (Orgs.). Professor reflexivo no Brasil: gênese e crítica de um conceito. São Paulo: Cortez, 2002. 
PIMENTA, Selma Garrido (Orgs.). Saberes pedagógicos e atividade docente/textos Edson Nascimento Campos [et. al.]; 4o ed. São Paulo: Cortez - 2005.

PROGRAMA INSTITUCIONAL DE BOLSA DE INICIAÇÃO À DOCÊNCIA - PIBID - Detalhamento de SUBPROJETO de Licenciaturas: Ciências Biológicas. EDITAL № 02/2009 - CAPES/DEB.

SCHÖN, D. A. Formar professores como profissionais reflexivos. In: Nóvoa (org.) Os professores e a sua formação, Lisboa, Dom Quixote 1992.

ZABALZA, Miguel Ángel. Diários de aula: um instrumento de pesquisa e desenvolvimento profissional. Artmed Editora, 2004.

ZEICHNER, Kenneth M.. Uma análise crítica sobre a "reflexão" como conceito estruturante na formação docente. Educ. Soc., Campinas, v. 29, n. 103, Aug. 2008. 